The senior author of each article has confirmed that the ethical aspects of these studies have been approved (a) for clinical studies by the Institution or an Ethics Committee and, if applicable, that informed patient consent has been obtained, (b) for experimental studies, involving the use of animals, by the institution and that the animals have been treated according to good practice.

\title{
Annual Meeting of the European Academy of Anaesthesiology 2001, 28 August-1 September 2001: Graz, Austria
}

\section{GRAZ-01-1}

Serum and cerebrospinal fluid S100b protein and neuron-specific enolase in relation to postoperative cognitive dysfunction in orthopedic patients

E. Stamataki, M. Vlonjou, I. Kiriou, A. Volanaki,

C. Psachoulia

Evangelismos Hospital, Athens, Greece

Introduction: The incidence of postoperative cognitive dysfunction (PCD) is high in the elderly undergoing hip fracture fixation. We assessed serum (s) and cerebrospinal fluid (csf) S100b protein and neuron-specific enolase (NSE) in relation to PCD in these patients.

Methods: In 26 females and 10 males, $83 \pm 7.5 \mathrm{yr}$ ASA I-III undergoing hip fracture fixation under spinal anaesthesia, we measured $s$ and csf NSE and S100b the day of operation. We assessed preoperative cognitive function (PreCF) as: 1 Normal $n=12$; 2 Slow, difficult $n=14 ; 3$ Confusion/delirium $n=6$; 4 Dementia $n=4$; and early PostCF as unchanged and deteriorated graded as: 1 Communication/ memory gaps, 2 Lethargy, 3 Confusion/Delirium,

Serum and csf S100 in postoperative cognitive dysfunction

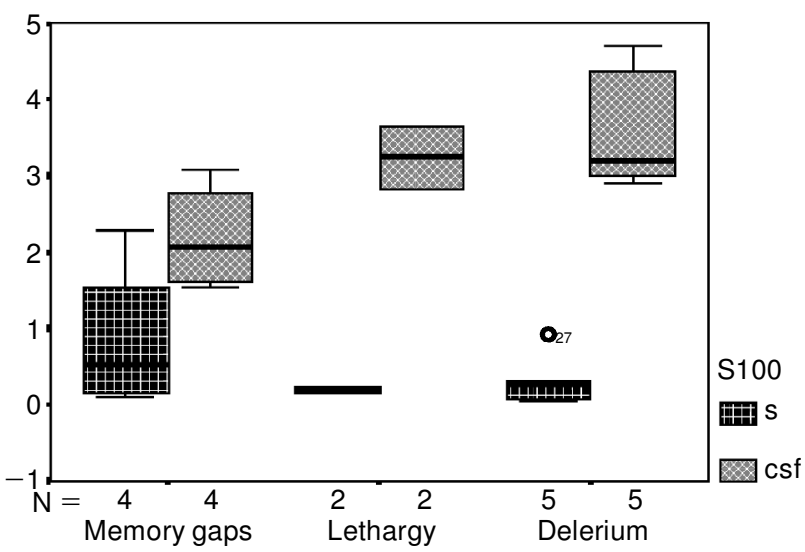

4 Dementia. Paired and unpaired $t$-tests were used for statistical analysis.

Results: sNSE and S100b were higher $P>0.000$ and lower $P>0.000$ respectively than csf values in all patients. There was no significant difference between unchanged and deteriorated patients overall. Eleven out of thirty-six patients (30\%), including two with normal PreCF, deteriorated: memory gaps 4, lethargy 2, delirium 5. In lethargic and delirious patients csfS100b was high.

Conclusions: sNSE and sS100b differed significantly compared to their csf values. Only csfS100b seems predictive of PCD suggesting that in severe PCD neuronal damage might already be in progress. Normal PreCF decreases the probability of PCD.

\section{GRAZ-01-2}

Only high dose rofecoxib reduces secondary hyperalgesia in an inflammatory pain model in volunteers

B. Gustorff*, T. Sycha ${ }^{\dagger}$, S. Anzenhofer ${ }^{*}$, M. Malec ${ }^{\Uparrow}$, H. G. Kress* ${ }^{*}$ L. Schmetterer ${ }^{\Uparrow \ddagger}$

Depts of ${ }^{*}$ Anaesthesia and General Intensive Care

Medicine (B), "Neurology and "Clinical Pharmacology,

*Institute of Medical Physics, University of Vienna, Austria

Introduction: The enzyme cyclo-oxygenase 2 (COX 2) is expressed in the central nervous system and may play a role in central pain mechanisms. Secondary hyperalgesia in the experimental sunburn pain model is explained by central sensitization. Our aim was to see whether rofecoxib, a new selective COX 2 inhibitor, reduces the area of secondary hyperalgesia around sunburn.

Methods: After approval by the Ethics Committee 42 volunteers were included in this randomized, placebo-controlled, double-blind cross-over study (2 sessions, interval 2 weeks). Twenty hours after 
UVB-irradiation of a circular spot $(\mathrm{r}=2.5 \mathrm{~cm})$ at thrice the minimal erythema dose on the ventral side of the upper leg, volunteers received a single oral dose of rofecoxib $50 \mathrm{mg}, 250 \mathrm{mg}, 500 \mathrm{mg}$ or placebo. Pinprick testing was performed at baseline and $6 \mathrm{~h}$ after medication to assess the area of secondary hyperalgesia around the sunburn. Repeated measure ANOVA was used for analysis.

Results: Compared to baseline the area of secondary hyperalgesia was reduced by $20 \%$ during placebo, by $29.4 \%(50 \mathrm{mg}), 25.5 \%(250 \mathrm{mg})$ and $38 \%$ $(P<0.032)(500 \mathrm{mg})$ with rofecoxib.

Conclusions: Only high dose rofecoxib $(500 \mathrm{mg}$ ) significantly reduced the area of secondary hyperalgesia in the sunburn pain model $(P=0.032)$. No difference was found between placebo and rofecoxib 50 or $250 \mathrm{mg}$. COX 2 may play a role in the central mechanisms of hyperalgesia in this human pain model.

\section{GRAZ-01-3}

\section{Treating low back pain with an extract} of Harpagopbytum that inhibits

\section{cytokine release}

S. Chrubasik*, B. Fiebich*, A. Black ${ }^{\dagger}$, S. Pollak ${ }^{*}$

*University Dept. of Forensic Medicine, Freiburg, Germany and ${ }^{\dagger}$ University Dept. of Anaesthesia, Bristol, UK

Introduction: A proprietary extract of Harpagophytum with daily doses of harpagoside 50 and $100 \mathrm{mg}$ produced dose-dependent analgesia in patients suffering from low back pain [1]. We report some intermediary in vitro effects of another proprietary extract, Doloteffin ${ }^{\circledR}$, and pilot comparisons of its clinical effectiveness with that of placebo and the selective COX 2 inhibitor, rofecoxib.

Methods: The effect of Doloteffin ${ }^{\circledR}$ on in vitro mediator release was assessed as previously described $[2,3]$. In two randomized double-blind studies, a total of 206 patients with acute exacerbation of low back pain consented to receive a dose providing 50-60 mg harpagoside/d ( $\mathrm{H}, \quad n=98)$, placebo $(\mathrm{P}, n=55)$ or rofecoxib ( $\mathrm{R}, n=44)$. After 4 weeks of treatment the outcome was assessed by the proportion of pain-free patients and by established indices of degrees of pain relief.

Results: In the in vitro studies, the approximate $\mathrm{IC}_{50}$ $\left(\mu \mathrm{g} \mathrm{mL}^{-1}\right)$ values of the extract for release from human monocytes were: PG-E $\mathrm{E}_{2}(\mathrm{COX} 1)$ undetectable, PG-E $2(\mathrm{COX} 2) 400, \mathrm{TNF}_{\alpha} 700, \mathrm{IL}_{1 \beta} 70$ and $\mathrm{IL}_{6} 900$ (harpagoside alone had no effect). In the clinical studies, $18 \%$ of patients in $\mathrm{H}, 2 \%$ in $\mathrm{P}$ and $11 \%$ in $\mathrm{R}$ were pain-free after 4 weeks of treatment (though a somewhat greater proportion of $\mathrm{R}$ patients failed to complete the study because of side-effects).
The outcome variables in $\mathrm{H}$ differed significantly from those in $\mathrm{P}$ but not from those in $\mathrm{R}$. No specific adverse effects were observed in $\mathrm{H}$ but there tended to be to more severe gastrointestinal side effects in $\mathrm{R}$. Conclusions: Doloteffin ${ }^{\circledR}$ is a potent inhibitor of cytokine release and a weak inhibitor of $\mathrm{COX} 2$. It produces complete pain relief in about $20 \%$ of low back pain patients, being more effective than placebo. It remains to be determined, with adequate patient numbers, whether Doloteffin ${ }^{\circledR}$ is more or less effective than rofecoxib to any clinically useful degree. The lower risk for gastrointestinal adverse events makes either of them preferable to non-selective COX inhibitors in the treatment of osteoarthritic pain.

\section{References}

1. Chrubasik S, et al. Eur J Anaesthesiol 1999; 16: 118-121.

2. Fiebich BL, et al. Neuropharmacology 2000; 39: 2205-2213.

3. Fiebich BL, et al. Phytomedicine 2001; 8: 28-30.

\section{GRAZ-01-4}

\section{Treating low back pain with a Salix extract that inhibits COX 2 and the release of cytokines}

S. Chrubasik, B. Fiebich, A. Black ${ }^{*}$, S. Pollak

University Dept. of Forensic Medicine, Freiburg, Germany and ${ }^{*}$ University Dept. of Anaesthesia, Bristol, UK

Introduction: The proprietary Salix extract, Assalix $^{\circledR}$, with $240 \mathrm{mg}$ of salicin day ${ }^{-1}$ produced complete analgesia in $40 \%$ of patients with low back pain [1] and significant reduction of hip and knee pain [2]. We report some intermediary in vitro effects of Assalix ${ }^{\circledR}$ as well as reaffirming its overall clinical effectiveness.

Methods: The effect of Assalix ${ }^{\circledR}$ on in vitro mediator release was assessed as previously described [3,4]. In open controlled clinical studies, 679 patients with acute exacerbation of low back pain consented to receive extract providing $120 \mathrm{mg}$ salicin day ${ }^{-1}$ $\left(\mathrm{W}_{120}, n=115\right), 240 \mathrm{mg}$ salicin day ${ }^{-1}\left(\mathrm{~W}_{240}, n=\right.$ 224) or conventional orthopaedic treatment (C, $n=$ 335) that included rofecoxib ( $R$ ) in 114 patients. The outcome was assessed after 4 weeks by the proportions of pain-free patients and by established indices of degree of pain relief.

Results: In the in vitro studies, the approximate $\mathrm{IC}_{50}\left(\mu \mathrm{g} \mathrm{mL} \mathrm{m}^{-1}\right)$ values of the extract were: PG-E

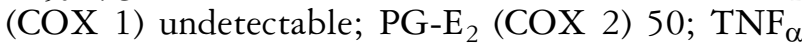
200, $\mathrm{IL}_{1 \beta} 110 ; \mathrm{IL}_{6} 200$; of salicylate $\mathrm{PG} \mathrm{E}_{2}(\mathrm{COX} 1)$ undetectable, PG $\mathrm{E}_{2}$ (COX 2) 16 (salicin alone had no effect). In the clinical studies, $40 \%$ of the patients 
in $\mathrm{W}_{240}, 19 \%$ in $\mathrm{W}_{120}$ and $18 \%$ in $\mathrm{C}$ were pain-free after 4 weeks of treatment. The pain index improved by $36 \%\left(\mathrm{~W}_{240}\right), 18 \%\left(\mathrm{~W}_{120}\right)$ and $25 \%(\mathrm{C})$, respectively. Treatment with Assalix ${ }^{\circledR}$ was significantly cheaper than conventional treatment. Multivariable modelling to examine for possible confounding effects of duration and severity of initial pain tended to identify $\mathrm{W}_{240}$ as an independent explanator of better pain relief than $\mathrm{C}$. Treatment outcomes in $\mathrm{W}_{240}$ and $\mathrm{R}$ were similar. No specific adverse effects of Assalix ${ }^{\circledR}$ were observed except occasional allergic skin reactions.

Conclusions: Assalix ${ }^{\circledR}$ is a potent and selective inhibitor of COX 2 and a weak inhibitor of cytokine release. The high benefit-risk ratio supports its use in preference to non-selective NSAIDs in the treatment of osteoarthritic pain and as an economically sound alternative to expensive conventional treatments.

\section{References}

1. Chrubasik S, et al. Am J Med 2000; 109: 9-14.

2. Schmid B, et al. Z Rheumatologie 2000; 59: 314-320.

3. Fiebich BL, et al. Neuropharmacology 2000; 39: 2205-2213.

4. Fiebich BL, et al. Phytomedicine 2001; 8: 28-30.

\section{GRAZ-01-5}

Procalcitonin and C-reactive protein plasma concentrations during intermittent haemodialysis
A. A. Dahaba, P. H. Rehak, W. F. List
Karl Franzens University, Graz, Austria

Introduction: Both uraemia and bio-incompatibility of haemodialysis membranes could result in the systemic inflammatory response syndrome [1]. The aim of the study was to assess the plasma concentrations of PCT, one of the best markers of sepsis [2], and CRP in patients undergoing haemodialysis.

Methods: In 55 patients, without evidence of any systemic infection, blood samples were collected before and at the end of each haemodialysis session. PCT was assayed using an immunolumino-metric technique (LUMItest ${ }^{\circledR}$, B.R.A.H.M.S. diagnostica, Berlin, Germany).

Results: Mean PCT plasma concentration was mildly elevated $\left(>1.5 \mathrm{ng} \mathrm{mL}^{-1}\right)$. PCT significantly declined, with consecutive haemodialysis sessions, to normal plasma concentrations $\left(<0.5 \mathrm{ng} \mathrm{mL}^{-1}\right)$. There was no significant difference in the CRP plasma concentrations before and after haemodialysis or with time.

Conclusions: Elevated PCT concentrations may indicate inflammatory activity in uraemic patients,

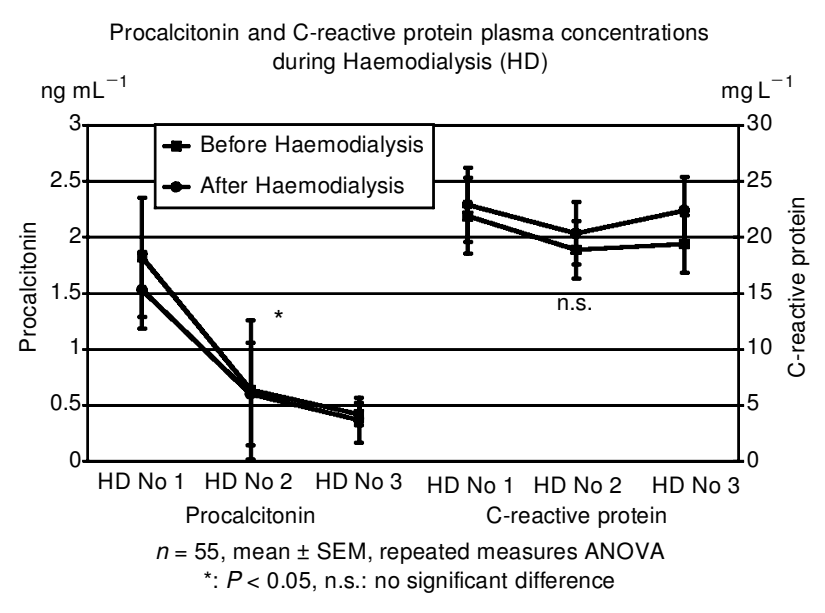

possibly resulting from endotoxins or endotoxin fragments crossing the membrane [1]. Due to its low molecular weight $(13 \mathrm{kD})$ PCT can pass the haemodialysis membrane but a larger molecule, e.g. CRP $(105.5 \mathrm{kD})$, is not lost in the dialysate.

\section{References}

1. Schmidt M, et al. Nephron 2000; 84: 187-188.

2. Assicot M, et al. Lancet 1993; 341: 515-518.

\section{GRAZ-01-6}

AS $/ 3{ }^{\circledR}$ neuromuscular transmission module (M-NMT) vs. mechanomyography for neuromuscular block monitoring A. A. Dahaba, F. von Klobucar, P. H. Rehak, W. F. List

Karl-Franzens University, Graz, Austria

Introduction: The AS $/ 3^{\circledR}$ (Datex-Ohmeda, Finland) neuromuscular transmission module (M-NMT) is a piezoelectric motion sensor for monitoring neuromuscular block. We compared this monitor with the Relaxometer mechanomyograph (MMG).

Methods: The two monitors were alternately attached to the left or right hands of 20 patients given rocuronium $0.6 \mathrm{mg} \mathrm{kg}^{-1}\left(2 \times \mathrm{ED}_{95}\right)$. T1, first twitch of the train-of-four (TOF) and the TOF ratio (T4:T1) were used to evaluate the neuromuscular block.

Results: There was no significant difference in the mean $\pm \mathrm{SD}(\mathrm{min})$ onset time and time to $0.8 \mathrm{TOF}$ ratio recovery, measured by the M-NMT $(1.5 \pm 0.3$, $49.4 \pm 8.1)$ compared to the MMG (1.8 \pm 0.6 , $50.9 \pm 9.9)$. However, the time to T1 $25 \%$ recovery was significantly longer when monitored by the M-NMT (25.6 \pm 8 ) compared to the MMG (20.2 \pm 6.3). According to a Bland and Altman analysis, 


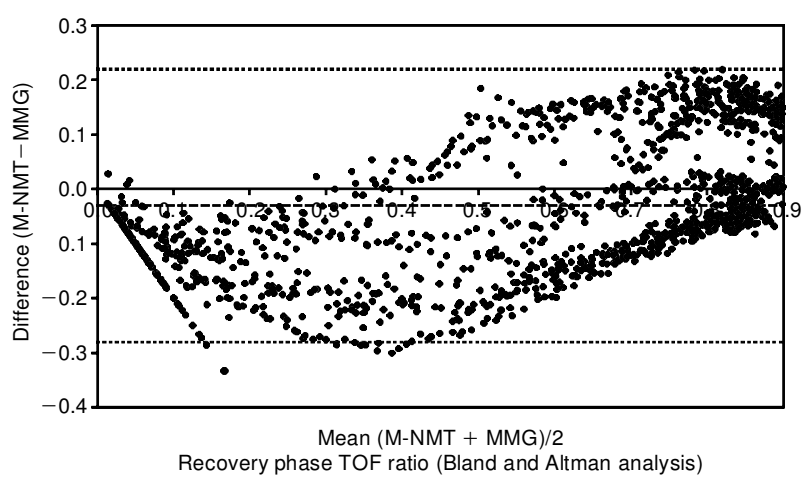

the TOF ratio bias (the difference between the two monitors) was -0.031 and the limits of agreement (bias $\pm 1.96 \mathrm{SD}$ ) were -0.281 and +0.22 (Fig. 1). Conclusions: The M-NMT module could accurately point the time to tracheal intubation as well as full recovery from neuromuscular block. However, it was less accurate in detecting the time to rocuronium repeat dose administration. M-NMT has the advantages of being incorporated in the anaesthesia monitor, its quick-fit sensor is small, simple to set up, and does not require a rigid support to the arm. Thus the M-NMT is a reliable clinical monitor in everyday anaesthesia practice.

\section{GRAZ-01-7}

Rocuronium vs. mivacurium equi-lasting doses for gynaecological laparoscopic surgery. A randomized double-blind study

A. A. Dahaba, E. Schweitzer, R. D. Fitzgerald,

S. Schwarz

\section{Lainz Hospital, Vienna, Austria}

Introduction: The variable, and often undefined, duration of gynaecological laparoscopy confronts the anaesthetist with the choice of the optimal neuromuscular relaxant. The aim of the study was to compare equi-lasting doses of a short-acting (mivacurium chloride) to an intermediate-acting (rocuronium bromide) relaxant, in patients undergoing laparoscopic gynaecological surgery.

Methods: Sixty patients were randomly allocated to receive either $0.2 \mathrm{mg} \mathrm{kg}^{-1}\left(3 \times \mathrm{ED}_{95}\right)$ mivacurium or $0.5 \mathrm{mg} \mathrm{kg}^{-1}\left(1.7 \times \mathrm{ED}_{95}\right)$ rocuronium, during propofol/fentanyl anaesthesia. T1, first twitch of the train-of-four (TOF) and TOF ratio (T4:T1) were used to evaluate neuromuscular block (NMB) using the Relaxometer mechanomyograph. The trachea was intubated when T1 was maximally suppressed. NMB was maintained at $25 \%$ T1 with equilasting doses of $0.075 \mathrm{mg} \mathrm{kg}^{-1}$ mivacurium or $0.15 \mathrm{mg} \mathrm{kg}^{-1}$ rocuronium.
Results: Mean \pm SD (min) mivacurium onset time $(1.9 \pm 0.4)$ was longer than that of rocuronium $(1.3 \pm 0.3) \mathrm{min}$. However, this did not yield a significant difference in intubating conditions between the two groups. Time to $25 \%$ T1 recovery and 0.8 TOF ratio recovery were significantly prolonged following rocuronium $(25.8 \pm 6.5,52.6 \pm$ 15.5) compared to mivacurium (19.9 $\pm 4.4,39.2 \pm$ 8.1). More patients, $22 / 30$, required mivacurium maintenance doses compared to $14 / 30$ patients in the rocuronium group. Arterial pressure significantly declined and 13/30 patients manifested erythema following mivacurium. Rocuronium (a6.93 per patient) was significantly less expensive than mivacurium (a8.96 per patient).

Conclusions: Equi-lasting doses of rocuronium were associated with faster favourable intubating conditions, haemodynamic stability, required less maintenance doses, were not associated with erythema, as well as being $23 \%$ less expensive than mivacurium.

\section{GRAZ-01-8}

ASA and severity of postoperative pain are prognostic factors for postoperative cardiovascular and respiratory complications

D. Dermitzaki, F. Chaniotaki, J. Kamarianakis, O. Fraidakis, A. Papaioannou, H. Askitopoulou University Hospital of Heraklion, Crete, Greece

Introduction: The significance of the preoperative general condition of surgical patients and the severity of postoperative pain were investigated in relation to postoperative cardiovascular and respiratory complications.

Methods: The ISPOCD multicentre database was retrospectively analysed for parameters of postoperative outcome. From a total of 1218 elderly patients, ASA I-III, who had undergone major surgery of $>2 \mathrm{~h}$ duration, 559 were selected who had complete data on the following postoperative parameters: CVS complications, minor (tachycardia, bradycardia, hypertension, hypotension), major (atrial fibrillation, A-V block, acute myocardial infarction, cardiac failure, cardiac arrest), RS complications, minor (atelectasis, pneumonia, hypoxaemia) and major (respiratory insufficiency). These parameters were analysed in relation to ASA and postoperative pain as assessed by the visual analogue scale (VAS). Statistical analysis was undertaken by the Somers, $\mathrm{D}$ test, Pearson and Spearman's correlation and logit model.

Results: ASA III patients had an increased risk of developing all types of cardiovascular complications 
(CI 95\% 0.04-0.14), hypoxaemia (CI 95\% 0.01-0.10) and respiratory insufficiency (CI 95\% 0.05-0.14). Also severe postoperative pain (VAS $>5$ ) was strongly related to cardiovascular (CI 95\% 0.01-0.08) and respiratory complications (CI 95\% 0.00-0.09). With respect to postoperative cardiovascular complications, the ASA grade was found to be the only independent factor of high prognostic value $(P<0.001)$, while the presence of postoperative hypoxaemia did not further increase the possibility of cardiovascular complications in patients ASA III. Regarding respiratory complications: both ASA III and severe postoperative pain were found to be prognostic factors $(P<0.0001)$, and their action was synergistic.

Conclusions: Surgical elderly patients with poor preoperative general condition were at increased risk of developing cardiovascular and respiratory complications especially in the presence of severe postoperative pain. It is essential that effective pain relief should be provided to ASA III patients undergoing major surgery.

\section{GRAZ-01-9}

Effects of remifentanil and fentanyl on intraocular pressure and on recovery E. Deusch ${ }^{*}$, S. Dolezal ${ }^{*}$, A. Michalek-Sauberer ${ }^{*}$, G. Scharbert ${ }^{*}$, A. Wedrich ${ }^{\dagger}$, S. Sator-Katzenschlager ${ }^{*}$ Depts of *Anaesthesiology and General Intensive Care and ${ }^{\dagger}$ Ophthalmology and Optometrics,

University of Vienna, Austria

Introduction: This study compares the effects on intraocular pressure (IOP) and the recovery characteristics of remifentanil/propofol with fentanyl/ propofol anaesthesia in 30 patients (ASA I, II), undergoing elective non-ophthalmic surgery [1].

Methods: After induction, patients were randomized to receive either a continuous infusion of remifentanil $0.25 \mu \mathrm{g} \mathrm{kg}^{-1} \min ^{-1}(n=15)$ or intermittent bolus doses of fentanyl $4 \mu \mathrm{g} \mathrm{kg}^{-1}(n=15)$ during maintenance of anaesthesia (continuous infusion of propofol supplemented with $70 \%$ air in $\mathrm{O}_{2}$ and intermittent bolus doses of vecuronium). Blood pressure, electrocardiography and heart rate were monitored throughout anaesthesia. IOP was determined before induction, during maintenance, after extubation and in the PACU with Perkins' handheld applanation tonometry by one 'blinded' ophthalmologist. Additionally recovery profiles of both anaesthesia regimens were compared. Statistical analysis was performed with $t$-test and ANOVA $(P<0.05)$.
Results: A significant IOP decrease was found during the whole maintenance of anaesthesia in both groups, but did not differ significantly between them. The emergence times and the late recovery of remifentanil were significantly faster compared with the fentanyl group.

Conclusions: Remifentanil and fentanyl are equally effective in reducing the IOP in unstressed non-ophthalmic surgery patients, but the emergence time in the remifentanil group is faster.

\section{Reference}

1. Guy J, et al. Anesthesiology 1997; 86: 514-524.
GRAZ-01-10

\section{Can 4-chloro-3-ethylphenol be used in-vitro} to differentiate between malignant hyperthermia susceptible and non-susceptible swine?

M. U. Gerbershagen, F. Wappler, M. Fiege, R. Weißhorn, F. V. Breunig, J. Schulte Am Esch Institution Department of Anaesthesiology, University Hospital Hamburg-Eppendorf, Germany

Introduction: The in-vitro contracture test with halothane and caffeine is the gold standard for diagnosis of malignant hyperthermia. This test has a sensitivity of $99.0 \%$ but only a specificity of $93.6 \%$ [1]. Therefore, an alternative drug is desirable which improves further malignant hyperthermia diagnosis. 4-chloro-3-ethylphenol recently has been shown to trigger $\mathrm{Ca}^{2+}$-induced $\mathrm{Ca}^{2+}$-release in skeletal muscle terminal cisternae [2]. The purpose of this study was therefore to investigate the ability of 4-chloro3-ethylphenol to distinguish between porcine malignant hyperthermia susceptible and normal specimens using the in-vitro contracture test.

Methods: After approval by the local animal care committee 10 malignant hyperthermia susceptible and 14 normal swine were anaesthetized and muscle biopsies taken. For the in-vitro contracture test, muscle specimens were exposed to cumulative administration of 4-chloro-3-ethylphenol $\left(12.5-200 \mu \mathrm{mol} \mathrm{L}^{-1}\right)$. The effects on contracture development were recorded. Data are expressed as medians and ranges. Group differences were analysed with the $U$-test.

Results: All malignant hyperthermia susceptible muscles demonstrated baseline contractures at $100 \mu \mathrm{mol} \mathrm{L}^{-1}$ (median/minimum/maximum: 7.1/2.4/ $12.3 \mathrm{mN})$ and $200 \mu \mathrm{mol} \mathrm{L}^{-1}(12.3 / 6.6 / 18.7 \mathrm{mN})$. In contrast, the specimens of normal swine did not exhibit any baseline contractures. The contractures 
were significantly greater in susceptible compared to normal muscles in all 4-chloro-3-ethylphenol concentration steps between $50 \mu_{\mathrm{mol} \mathrm{L}}^{-1}$ to $200 \mu \mathrm{mol} \mathrm{L}^{-1}$ and there was no overlap above a concentration of $75 \mu \mathrm{mol} \mathrm{L}^{-1}$.

Conclusions: Since no agent so far tested has revealed a clear differentiation in contracture development without overlap, 4-chloro-3-ethylphenol is a new and promising agent for presymptomatic malignant hyperthermia diagnosis.

\section{References}

1. Ording H, et al. Acta Anaesthesiol Scand 1997; 41: 955-966.

2. Larini F, et al. Mol Pharmacol 1995; 47: 21-28.

GRAZ-01-11

\section{Measurement of cardiac output by a new transoesophageal Doppler device after cardiac surgery. A comparison with the thermodilution technique \\ P. Jaeggi, C. Hofer, P. Fodor, A. Zollinger \\ Institute of Anaesthesiology, Triemli City Hospital \\ Zurich, Switzerland}

Introduction: Assessment of haemodynamics by transoesophageal Doppler devices (TDD) may be a non-invasive alternative to the pulmonary artery catheter [1]. In contrast to the TDD evaluated so far [2], the TDD (HemoSonic100 ${ }^{\circledR}$; Arrow, Reading, PA, USA) measures blood flow velocity and the diameter of the descending aorta. The aim of this study was to determine the accuracy and reliability of the new TDD compared to the thermodilution technique by PAC.

Methods: After haemodynamic stabilization in the ICU after routine cardiac surgery in 22 patients, cardiac index was determined using an iced water bolus (IWB). Continuous cardiac index (CCI) and TDD measurements were made at intervals of minimal $30 \mathrm{~min}$ (T1-T4). Routine therapy and monitoring was not influenced by the study and weaning from the ventilator was begun after the last measurement. Statistical analysis used linear correlation, Bland and Altman analysis and ANOVA with post hoc Bonferroni/Dunn correction. $P<0.05$ was considered as significant.

Results: Eighty-eight matched sets of data were obtained from 22 patients. Five sets were incomplete due to failed signal detection by the TDD. Haemodynamic variables at T1-T4 were stable $(P=$ $0.2-0.8)$. The correlation between TDD and IWB $(r=0.3)$ was found to be inferior to the correlation between CCI and IWB ( $r=0.8)$. Bland and Altman analysis revealed a mean bias of $0.23 \mathrm{~L} \mathrm{~min}^{-1} \mathrm{~m}^{-2}$ and limits of agreement (mean bias $\pm 2 \mathrm{SD}$ ) at -1.4 and $1.8 \mathrm{~L} \mathrm{~min}^{-1} \mathrm{~m}^{-2}$ for TDD and IWB, whereas mean bias was $0.1 \mathrm{~L} \mathrm{~min}^{-1} \mathrm{~m}^{-2}$ and limits of agreement were -0.5 and $0.8 \mathrm{~L} \mathrm{~min}^{-1} \mathrm{~m}^{-2}$ for CCI and IWB.

Conclusions: TDD was found to be less reliable and less accurate than CCI compared to IWB. TDD assessment was not possible in $6 \%$ of measurements due to failed signal detection by the device. Therefore, the TDD HemoSonic $100{ }^{\circledR}$ cannot be recommended as a sole device for monitoring cardiac index in patients after cardiac surgery.

\section{References}

1. Madan AK, et al.J Trauma 1999, 46: 607-612.

2. DiCorte CJ, et al. Ann Thorac Surg 2000; 69: 1782-1786.

\section{GRAZ-01-12}

Vascular cell adhesion molecule-1 (VCAM-1) on alveolar epithelial cells mediates macrophage adherence during hypoxia

S. Kneller, R. C. Schimmer, T. Pasch, B. Beck-Schimmer Institute of Anaesthesiology, University Hospital Zurich, Switzerland

Introduction: Vascular cell adhesion molecule-1 (VCAM-1) is an important adhesion molecule in many inflammatory processes of the lung. We recently showed significant in-vitro upregulation of VCAM-1 on alveolar epithelial cells (AEC) under hypoxic conditions. To further evaluate the biological function of the enhanced expression of VCAM-1 during hypoxia, adherence assays were performed. Our hypothesis was that a reduction in oxygen tension might induce adhesion of alveolar macrophages to AEC through VCAM-1/VLA-4 interaction.

Methods: AEC were harvested from lungs of male Long-Evans rats using porcine elastase, and cultured to confluency. Cells were exposed to hypoxia $\left(5 \% \mathrm{O}_{2}\right.$, $\left.37^{\circ} \mathrm{C}, 5 \% \quad \mathrm{CO}_{2}\right)$ or normoxia $\left(21 \% \mathrm{O}_{2}, 37^{\circ} \mathrm{C}\right.$, $5 \% \mathrm{CO}_{2}$ ) for $2 \mathrm{~h}$. Pulmonary alveolar macrophages, (broncho-alveolar lavage fluid of rats), were washed and added to the AEC for hypoxia or normoxia $(0.5 \times$ $10^{6}$ cells/well). At the same time, AEC were incubated with a polyclonal rabbit anti-rat VCAM-1 antibody, while AEC control wells contained rabbit IgG (Santa Cruz Biotechnology) $\left(10 \mu \mathrm{g} \mathrm{mL}^{-1}\right)$. After $20 \mathrm{~min}$ incubation, cells were carefully washed to eliminate non-adherent cells, and adherent cells counted.

Results: Mean \pm SEM, and significance of differences between groups assessed by two-tailed $t$-test. 


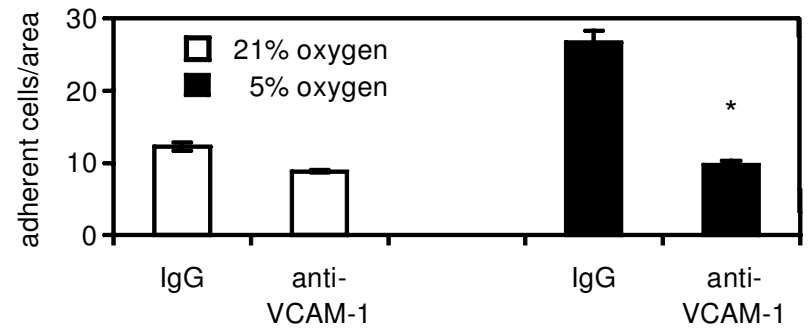

Macrophage adherence to AEC increased by $118 \%$ under hypoxia (Fig. 1). This increased adhesion could be blocked by $95 \%$ with a VCAM-1 antibody. Conclusions: Macrophage adherence to AEC under hypoxia is mainly VCAM-1 dependent. The biological effects and consequences remain to be elucidated.

\section{GRAZ-01-13}

The effect of GA vs. spinal anaesthesia on peripheral lymphocytes subsets

Ola Leheta ${ }^{*}$, Mohammed Alsharkasy ${ }^{\dagger}$

Depts of ${ }^{*}$ Clinical Pathology and ${ }^{\dagger}$ Anaesthesia, Suez Canal University, Egypt

Introduction: Innate and acquired immunity play pivotal roles in the host defence response. Pain, stress, necrotic tissue and invading micro-organisms are known modulators of the complex immune response of patients undergoing major surgery. General anaesthesia (GA) may substantially alter immune function with potential impact afterwards. We investigated the effects of GA and spinal anaesthesia (SA) on the cellular immune response.

Methods: 32 patients, age 20-45 yr, ASA I-II, who had undergone lower abdominal operations under GA or SA were studied. Blood was withdrawn immediately before GA/SA (A) and $30 \mathrm{~min}(\mathrm{~B})$ and $24 \mathrm{~h}$ (C) after surgery. Complete blood picture (Cell Dyne automated counter), lymphocyte subsets (flow cytometry), and two coloured fluorescent monoclonal antibodies were used to determine the lymphocyte subsets: CD14+ CD45+ (lymphocyte gating), $\mathrm{CD} 3+\mathrm{CD} 19-(\mathrm{T}$ cells $), \mathrm{CD} 8-\mathrm{CD} 4+$ ( $\mathrm{T}$ helper), $\mathrm{CD} 4-\mathrm{CD} 8+(\mathrm{T}$ cytotoxic), CD3$\mathrm{CD} 19+(\mathrm{B}$ cells) and $\mathrm{CD} 3+\mathrm{CD} 25+$ (activated T lymphocytes).

Results: Data are expressed as mean $\pm \mathrm{SD}$. The $\%$ of total lymphocytes, T helper, T cytotoxic, B lymphocytes, activated $T$ cells and $C D 4 / C D 8$ ratio in the three samples were compared. GA decreases both $\mathrm{T}$ lymphocyte subsets numbers and activity also it increase the B cell number. On the other hand SA does not interfere with $\mathrm{T}$ lymphocytes subsets or $\mathrm{B}$ cells lymphocytes subsets nor $\mathrm{T}$ cell activation. Conclusions: GA interferes with both $\mathrm{T}$ lymphocyte subsets numbers and activity and this may explain the clinically recognized disturbance of human immunity after surgery and GA; also GA increases the number of $B$ cells but the decrease in $T$ helper cells may interfere with $B$ cell activation. Spinal anaesthesia does not interfere with the normal cellular and humoral immune responses. Consequently $\mathrm{SA}$ is preferred to GA in patients for lower abdominal operations especially those with compromised immunity. T helper cell subsets and cytokines secreted by different lymphocyte types must be measured to identify the effect of both types of anaesthesia, as it was known that TH1 cells are responsible for controlling cell mediated immunity while TH2 cells are more effective in inducing humoral immunity. Timing of estimation of lymphocyte subsets must be prolonged after anaesthesia to determine when it returns to normal using different techniques of GA to determine which has the least immunosupressive effect on patients' immune response.

\section{GRAZ-01-14}

\section{Audit of paravertebral block in breast cancer surgery J. Mitic, C. Stirrup, G. Browne \\ Dept. of Anaesthetics, The Royal Marsden Hospital, London, UK}

Introduction: Breast cancer surgery is associated with postoperative pain, nausea and vomiting despite advances in medical treatment. The aim of this study was to assess the efficacy of the paravertebral block by evaluation of the verbal analgesic score (VAS) in the recovery room and $24 \mathrm{~h}$ postoperatively and the incidence of postoperative nausea and vomiting (PONV).

Methods: We studied 77 patients, status ASA IV, undergoing elective breast cancer surgery. Paravertebral block (unilateral or bilateral) was performed after general anaesthesia was induced; two of the patients had paravertebral block under local anaesthetic and intravenous sedation only.

Results: Seventy-seven patients completed the study. Statistical analysis showed a significant decrease in VAS in the recovery room and $24 \mathrm{~h}$ after operation. The incidence of nausea was noted in $22 \%$ of the patients, $3 \%$ of them had an episode of vomiting.

Conclusions: Paravertebral block can be used for breast cancer surgery as a method to decrease 
requirements for conventional postoperative analgesia and incidence of PONV.

\section{Reference}

1. Brown IDL. Reg Anaesth Analg 1996; 18: 293-300.

\section{GRAZ-01-15}

\section{Isoflurane binds to presynaptic snare proteins}

P. Nagele ${ }^{* \dagger}$, W. J. Placzek* , C. M. Crowder ${ }^{*}$

*Dept. of Anesthesiology, Washington University,

St. Louis, MO, USA and ${ }^{\dagger} D e p t$. of Anesthesiology and

Intensive Care Medicine, University of Vienna, Austria

Introduction: The molecular mechanism of action of volatile anaesthetics remains unknown. Recent results show marked effects of volatile anaesthetics on postsynaptic ligand-gated ion-channels as well as on presynaptic neurotransmitter release. In this study, we tried to elucidate the role of presynaptic SNARE proteins in the mechanism of volatile anaesthetic action, as implicated by recent genetic findings. Neuronal SNARE proteins (SNAP-25, syntaxin, and VAMP) interact with each other and are essential for synaptic vesicle exocytosis.

Methods: His $_{6}$-tagged recombinant rat SNARE proteins were expressed in BL21(DE3) bacteria and purified by Ni-NTA-agarose chromatography and FPLC. Binding of isoflurane to SNARE proteins was measured by ${ }^{19} \mathrm{~F}-\mathrm{NMR}$. Resulting $\mathrm{T}_{2}$ times are indicative of binding when significantly lower than buffer. NMR measurements were performed at various isoflurane concentrations.

Results: Recombinant SNARE proteins showed distinctively different isoflurane binding characteristics. Rat SNAP-25 bound isoflurane in a dosedependent manner at clinical concentrations (0.1-0.6 mM), whereas rat syntaxin showed nonsaturable binding over a 100-fold range of isoflurane concentrations $(0.06-6.0 \mathrm{mM})$. These results are suggestive of a few high-affinity binding sites on rat SNAP-25 and of many low-affinity binding sites on rat syntaxin. VAMP produced $\mathrm{T}_{2}$ values comparable to buffer alone and did therefore not show binding of isoflurane.

Conclusions: In this study, we were able to identify a neuronal presynaptic protein, SNAP-25, that binds isoflurane at clinical concentrations. Binding of isoflurane to SNAP-25 might interfere with its physiological functions, particularly the interaction with other SNARE proteins. Thus, our finding might explain how volatile anaesthetics reduce presynaptic neurotransmitter release.

\section{GRAZ-01-16}

Improved outcome after global cerebral ischaemia due to cardiocirculatory arrest in transgenic rats expressing baculovirus broad spectrum caspase inhibitor $\mathrm{p} 35$

S. A. Padosch, E. Popp, P. Teschendorf,

J. J. Krumnikl, P. Vogel, J. Motsch, E. Martin, B. W. Böttiger

Dept. of Anaesthesiology, University of Heidelberg, Germany

Introduction: In contrast to necrosis, apoptosis represents a pattern of cell damage associated with an active intracellular death program. Recent data indicate that cardiac arrest is followed by neuronal apoptosis [1]. The aim of this study was to determine the effects of antiapoptotic baculovirus protein p35 on survival and neurological recovery following cardiac arrest.

Methods: After approval by the animal care committee and in a randomized and blinded setting, cardio-circulatory arrest was induced in p35 transgenic rats and their non-transgenic littermates by electrical fibrillation of the heart. Following $6 \mathrm{~min}$ of cardiac arrest, cardio pulmonary resuscitation (CPR) was carried out as described previously [1]. After restoration of spontaneous circulation (ROSC), animals were allowed to survive for 7 days. At $24 \mathrm{~h}$, 3 days, and 7 days after ROSC, animals were tested according to a neurological deficit score (NDS; $100=$ worst; $0=$ best [2]).

Results: No differences between groups were observed with regard to weight, duration of CPR, body temperature, mean arterial pressure, and results of arterial blood-gas analyses. The rate of ROSC was higher in p35 transgenic animals (92\%; $n=12 / 13)$ than in non transgenic controls $(68 \%$; $n=17 / 25 ; P=0.09) ;$ and $85 \%(n=11)$ of $\mathrm{p} 35$ transgenic animals survived for 7 days, as compared to $52 \%(n=13)$ of controls $(P<0.05)$. A neurological recovery (worst NDS minus best NDS) below 30 was observed in $45 \%$ of transgenic animals and in $85 \%$ of non-transgenic animals $(P=0.055)$.

Conclusions: Following $6 \mathrm{~min}$ of cardiac arrest, 7-day survival was significantly better in p35 transgenic animals than in non-transgenic controls. Therefore, antiapoptotic baculovirus protein p35 may play a role in postischaemic recovery following cardiac arrest.

\section{References}

1. Böttiger BW, et al. J Cereb Blood Flow Metab 1998; 18: 1077-1087.

2. Katz L, et al. J Cereb Blood Flow Metab 1995; 15: 1032-1039. 


\section{GRAZ-01-17}

Assessment of neuroprotective properties of the synthetic caspase inhibitor $\mathrm{z}$-devd-fmk after global cerebral ischaemia due to cardiac arrest in rats

S. A. Padosch, P. Teschendorf, J. J. Krumnikl, P. Vogel, J. Motsch, E. Martin, B. W. Böttiger Dept. of Anaesthesiology, University of Heidelberg, Germany

Introduction: In contrast to necrosis, apoptosis represents a pattern of cell damage associated with an active intracellular death program. Recent data indicate that cardiac arrest (CA) is followed by neuronal apoptosis [1]. The aim of this study was to determine the effects of the inhibition of caspases on neuronal degeneration and outcome following CA.

Methods: After approval by the animal care committee, rats were subjected to CA as described previously [1]. After restoration of spontaneous circulation (ROSC), intracerebroventricular (i.c.v.) injections were carried out in the following groups: Group 1. Z-DEVD-FMK (caspase inhibitor; $2.25 \mu \mathrm{g} \times 2)$ i.c.v. $0.5 \mathrm{~h}$ and $24 \mathrm{~h}$ after CA; Group 2 . Z-FA-FMK (control drug; $2.25 \mu \mathrm{g} \times 2$ ) i.c.v. $0.5 \mathrm{~h}$ and $24 \mathrm{~h}$ after CA; Group 3. Z-DEVD-FMK $(60 \mathrm{ng} / \mathrm{h})$ i.c.v. continuously 7 days after CA; Group 4. cerebrospinal fluid i.c.v. continuously 7 days after CA. 7 days after ROSC coronal sections of the brain at the dorsal hippocampal level were taken and stained with cresyl violet and the TUNEL technique. Viable and TUNEL positive neurons were counted in the hippocampal CA1 sector. At $24 \mathrm{~h}, 3$ days, and 7 days after ROSC, animals were tested according to a neurological deficit score (NDS). All experiments were performed in a randomized and blinded setting.

Results: At day 7, neuronal degeneration with condensed chromatin in TUNEL + neurons was observed in all groups in the hippocampal CA1 sector. There were no differences regarding the number of viable and TUNEL + neurons, and the NDS.

Conclusions: The detection of TUNEL + neurons with condensed chromatin suggests an apoptosisassociated pattern of neuronal degeneration. Inhibition of caspases with Z-DEVD-FMK did not show any positive effect on neuronal degeneration and outcome in rats. The present data suggest that neuronal apoptosis after CA is not solely caused by the activation of caspases.

\section{Reference}

1. Böttiger BW, et al. J Cereb Blood Flow Metab 1998; 18: 1077-1087.
GRAZ-01-18

Probability of defibrillation success combining frequency and amplitude in porcine models of cardiac arrest

K. Rheinberger, U. Achleitner, A. C. Krismer, W. Lingnau, K. H. Lindner, V. Wenzel, A. Amann Dept. of Anaesthesia and General Intensive Care, Leopold-Franzens-University of Innsbruck, Austria

Introduction: Defibrillation outcome is correlated to the mean frequency (FREQ) of the ventricular fibrillation (VF) ECG signal. The aim of the study was to increase the predictive power of FREQ using mean amplitude (AMPL) in addition.

Methods: We examined 64 VF ECG signals from different porcine models of cardiac arrest. The two 10 -s segments between 30 and $10 \mathrm{~s}$ before the first defibrillation shock were bandpass filtered in the range from 4.33 to $30 \mathrm{~Hz}$. FREQ, AMPL and a new survival index (SI), a linear combination of FREQ and AMPL, were estimated for every segment. As a measure of predictive power, for all values of FREQ and SI, we estimated the probabilities to obtain return of spontaneous circulation (ROSC) or not (NONROSC). These two probabilities sum up to one.

Results: Figures 1 and 2 show the probabilities for ROSC and NONROSC depending on the value of FREQ or SI, respectively. FREQ is a poor predictive parameter for values between $6.90 \mathrm{~Hz}$ and $8.35 \mathrm{~Hz}$. The parameter region, where SI predicts poorly between ROSC and NONROSC is much smaller compared to FREQ.

Discussion: Although ECG amplitude is subject to a great interindividual variety, using AMPL in addition to FREQ increases predictive power remarkably.

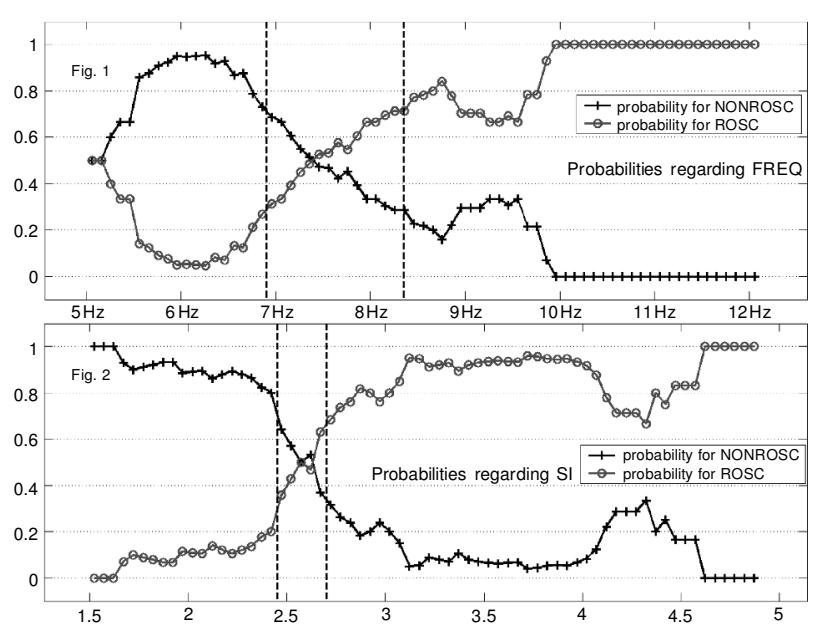




\section{GRAZ-01-19}

\section{Oestrogen decreases mu, but not kappa opioid antinociception in visceral pain}

A. Sandner-Kiesling * , R. L. James ${ }^{\dagger}$, J. C. Eisenach ${ }^{\dagger}$

${ }^{*}$ Karl Franzens University, Graz, Austria and ${ }^{\dagger}$ Wake

Forest University School of Medicine, Winston-Salem,

NC, USA

Introduction: Although systemic morphine, a mu opioid receptor (MOR) agonist, produces analgesia in somatic pain, it lacks efficacy in labour pain [1]. Kappa OR (KOR) agonists' analgesic properties in labour pain are controversial [2]. Our hypothesis is that oestrogen reduces MOR-, but not KORinduced antinociception in an animal model related to labour pain.

Methods: After institutional approval, 24 ovariectomized female Sprague-Dawley rats (205-305 g) were anaesthetized with halothane and acutely instrumented with tracheal, jugular venous and carotid arterial cannulae. Metal rods were inserted in the uterine cervix (midline laparotomy). After stabilization the cervix was distended by manual separation of the rods (forces 25-100 g), and reflex rectus abdominis EMG activity recorded. After determining the stimulus-response relationship, we measured inhibition of reflex activity by morphine and the KOR agonist (-)U50,488 applied i.v. in a cumulative manner at 5-min intervals, defined by preliminary experiments. To test effects of oestrogen, $17 \beta$-estradiol (ERT) or placebo pellets were implanted s.c. 1 week earlier. Groups were compared by 2 -way ANOVA; $P<0.05$ being significant.

Results: Morphine $\left(0.1,0.3,1 \mathrm{mg} \mathrm{kg}^{-1}\right)$ and (-)U 50,488 (0.1, 0.3, $\left.1,3 \mathrm{mg} \mathrm{kg}^{-1}\right)$ produced dose dependent inhibition of reflex activity in the placebo groups ( $n=6$ each), a complete blockade at the highest dose, and reversal by naloxone, $1 \mathrm{mg} \mathrm{kg}^{-1}$. Log linear regression analysis demonstrated $\mathrm{ED}_{50}$ of 0.03 and $0.05 \mathrm{mg} \mathrm{kg}^{-1}$, respectively. However, ERT attenuated the inhibitory properties of morphine (no inhibition up to $1 \mathrm{mg} \mathrm{kg}^{-1}$ ), but not of (-)U 50,488 $\left(0.1-3 \mathrm{mg} \mathrm{kg}^{-1}\right)(n=6$ each). Comparison of both (-)U50,488 groups revealed no difference, in contrast to morphine $\left(0.3-1 \mathrm{mg} \mathrm{kg}^{-1}\right)$.

Conclusions: This is the first report in a model of visceral pain suggesting that morphine's lack of efficacy in labour pain may be related to elevated oestrogen levels. KOR agonists remain unaffected by oestrogen. Therefore KOR agonists may be beneficial for the treatment of labour pain compared to MOR agonists.

Acknowledgements: Supported in part by $\mathrm{NIH}$ grant GM35523 and by the Austrian Science Fund.

\section{References}

1. Olofsson C, et al. Br J Obstet Gynaecol 1996; 103: 968-972.

2. Kest B, et al. Anesthesiology 2000; 93: 539-547.

\section{GRAZ-01-20}

\section{Pharmacokinetic/-dynamic modelling of} the new propofol prodrug GPI-15715 in rats M. Schywalsky*, H. Ihmsen*, A. Tzabazis*, J. Vornov ${ }^{\dagger}$, E. Burak ${ }^{\dagger}$, H. Schwilden* *Dept. of Anaesthesiology, University of Erlangen-Nuremberg, Erlangen, Germany and ${ }^{\dagger}$ Guilford Pharmaceuticals, Baltimore, USA

Introduction: GPI-15715 (G) is a new watersoluble prodrug, which is metabolized to propofol by hydrolysis. We studied the pharmacokinetics and pharmacodynamics of $G$ in rats.

Methods: Nine male Sprague-Dawley rats (BW: $398 \pm 31 \mathrm{~g}$ ) received a bolus of $40 \mathrm{mg}$ G. Arterial samples were drawn until $90 \mathrm{~min}$ after bolus dose and plasma concentrations of $G$ and propofol were determined by HPLC. Pharmacokinetics were analysed using compartment models whereby the elimination from the central compartment of $G$ was used as drug input for the central compartment of propofol. The EEG was recorded continuously and the median frequency of the power spectrum used as a measure of the hypnotic effect. Blood pressure was recorded continuously via the arterial catheter.

Results: A maximum propofol concentration of $6.8 \pm 1.7 \mu \mathrm{g} \mathrm{mL}^{-1}$ was reached $3.4 \pm 0.2 \mathrm{~min}$ after bolus administration. Pharmacokinetics could be described by a one-compartment model for $G$ and a two-compartment model for propofol. The elimination (hydrolysis) rate constant of $G$ was $0.56 \pm$ $0.056 \mathrm{~min}^{-1}$. For propofol, the half-times were $4.4 \pm 0.5$ and $52 \pm 7 \mathrm{~min}$, the elimination rate constant was $0.055 \pm 0.002 \mathrm{~min}^{-1}$ and $\mathrm{V}_{c}$ was $5.4 \pm$ $0.2 \mathrm{~L} \mathrm{~kg}^{-1}$. Compared to propofol administered i.v. the bioavailability was estimated to $0.52 \pm 0.16$. The maximum EEG effect (EEG suppression for $4-$ $8 \mathrm{~s}$ ) occurred $6.5 \pm 1.2 \mathrm{~min}$ after administration of $\mathrm{G}$, baseline values of the EEG median frequency were regained $30 \mathrm{~min}$ after bolus dose. Pharmacodynamics could be described by a sigmoid $\mathrm{E}_{\max }$ model including an effect compartment $\left(\mathrm{k}_{\mathrm{e} 0}=0.37 \pm\right.$ $0.07 \mathrm{~min}^{-1}$ ). The half-maximum concentration was $\mathrm{EC}_{50}=2.9 \pm 1.5 \mu \mathrm{g} \mathrm{mL}^{-1}$. The mean arterial pressure decreased from initially $147 \pm 7 \mathrm{mmHg}$ to a minimum of $113 \pm 18 \mathrm{mmHg} 2 \mathrm{~min}$ after bolus dose and reached baseline values after $20 \mathrm{~min}$.

Conclusions: Compared to the known propofol formulations, propofol from GPI-15715 showed similar half-times and an increased volume of 
distribution, a delayed onset and a sustained duration of action.

\section{GRAZ-01-21}

\section{Urokinase receptor deficiency reduces neutrophil recruitment in sepsis and ameliorates survival \\ G. Theilmeier, J. Larmann, M. Dewerchin, \\ P. Carmeliet, H. Van Aken \\ Departments of Anaesthesia in the Universities of Leuven and Münster, Germany}

Introduction: Symptoms of generalized inflammatory syndromes are related to polymorphonuclear neutrophil (PMN) adhesion to microvascular endothelium and their consecutive extravazation. The urokinase receptor (u-PAR) has recently been shown to be critically involved in the regulation of the activity of $\beta$-integrin function. The role of $u-P A R$ in inflammation has not been fully elucidated.

Methods: PMN were percoll-purified from hind limb bone marrow of wild-type (wt) or u-PARdeficient $\left(^{-/-}\right)$mice and fluorescently labelled. PMN were superfused in a parallel plate flow chamber with a shear rate of $400 \mathrm{~s}^{-1}$ over resting or $\mathrm{TNF}_{\alpha}$ stimulated murine endothelial cells (ECs) grown on collagen coated coverslips. Firm adhesion in this system is mainly mediated by MAC-1/ICAM-1. PMN adhesion $\left(/ 20 \mathrm{~mm}^{2}\right.$ of the coverslip) is reported as percentage of wt-PMN adhesion to resting ECs. $\mathrm{u}-\mathrm{PAR}^{-1-}$ or wt mice were injected i.p. with 30 or $45 \mathrm{\mu g} \mathrm{g}^{-1}$ bodyweight $E$. coli endotoxin (LPS) and left ventricular performance (by transthoracic echocardiography), survival time and mortality were recorded.

Results: Compared to resting ECs adhesion of WT PMN increased to $172 \pm 34 \%$ after 6-h stimulation with $100 \mathrm{nM} \mathrm{TNF}_{\alpha}(n=5, P<0.01)$, while $\mathrm{u}-\mathrm{PAR}^{-1-}$ PMN completely failed to increase adhesion to activated endothelium $(99 \pm 26 \%$ vs. $73 \pm$ $26 \%, n=6 / 5, P=\mathrm{NS}$ resting vs. $\mathrm{TNF}_{\alpha}$ and $P<$ $0.01, \mathrm{u}^{-\mathrm{PAR}}{ }^{-1-}-\mathrm{TNF}_{\alpha}$ vs. wt-TNF $\mathrm{TN}_{\alpha}$ ). $68 \%$ of the

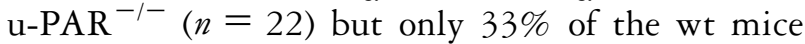
$(n=21)$ survived an injection of $30 \mu \mathrm{g} \mathrm{g}^{-1}$ LPS i.p. When $45 \mu \mathrm{g}$ LPS was injected, only a trend for decreased mortality was detected after $72 \mathrm{~h}$ ( $43 \%$ vs. $25 \%$ survival, $\mathrm{u} \mathrm{PAR}^{-1-}$ vs. wt, $n=21 / 20$ ) but a significantly prolonged time to death was observed ( $29 \pm 5$ h vs. $16 \pm 6 \mathrm{~h}, \mathrm{u}_{-} \mathrm{PAR}^{-1-}$ vs. wt). Increased survival was not fully explained by differences in LV function as $90 \mathrm{~min}$ after LPS injection shortening fraction $(69 \pm 3 \%$ vs. $62 \pm 2 \%$, u-PAR vs. wt, $n=5, P<0.05)$ and velocity of circumferential fibre shortening (Vcf) were similar or only marginally different between groups.
Conclusions: u-PAR expression on PMN is required for adequate $\mathrm{PMN}$ adhesion to activated EC. Lack of u-PAR protects mice from endotoxin induced systemic inflammatory responses and death, which is only in part related to cardiac function. Regulation of u-PAR mediated activation of integrins could be a suitable target for reducing inflammatory responses.

\section{GRAZ-01-22}

\section{Evaluation of a psychological risk-score for the prediction of outcome in anaesthesia and intensive care medicine}

T. Uhlig ${ }^{*}, \mathrm{~K}$. W. Kallus ${ }^{\dagger}$, P. Schmucker ${ }^{\rrbracket}$, K. Reinhart ${ }^{*}$

*Klinik für Anästhesiologie, Universität Jena, $\dagger$ Institut für Psychologie, Universität Graz, Austria and "Klinik für Anästhesiologie, Universität Lübeck, Germany

Introduction: Somatic scoring systems for the evaluation of severity of illness are commonly used in anaesthesia and intensive care medicine [1]. Although the momentary psychophysiological condition is known to be very important in the context of perioperative stress response, no psychological risk profile is known for the prediction of outcome in anaesthesia and intensive care medicine. The aim of these studies was to evaluate such a psychological scoring system on the basis of biopsychological stress theory.

Methods: By using Configural-Frequency-Analysis, a non-parametric statistical method to define types of persons by a configuration of attributes, healthy volunteers $(n=1300)$ and surgical patients $(n=900)$ were studied. Psychometric measurements of coping styles, state of recovery and mood were made by well-established inventories. After defining types on the basis of psychometric measurements an evaluation of outcome was made in the groups of surgical patients.

Results: The results show that in order to classify patients regarding high or low psychological risk information of habitual coping styles, state of recovery and mood-state are needed. Dependent on the psychological risk, profile length of ICU-stay varies. Low-risk patients left the ICU 1 day earlier. In addition this group of patients received a smaller amount of packed red blood cells after aortocoronary bypass grafting. There were significant differences in the sympatho-adrenergic stress response compared to high-risk patients. The psychological risk-score is independent from somatic risk factors.

Conclusions: The psychophysiological condition is important for perioperative outcome. It leaves 
additional information to somatic scoring systems.

\section{Reference}

1. Knaus WA, et al. Crit Care Med 1985; 13: 818-829.

GRAZ-01-23

\section{Lipid emulsions activate membrane currents in neuronal cells}

H. W. Weigt, M. Georgieff, E. M. Georgieff, K. J. Föhr

University Clinic of Anesthesiology, University of Ulm, Germany

Introduction: To date, it is assumed that emulsions alone exert no effect on cellular functions nor influence the pharmacokinetics, pharmacodynamics or anaesthetic and analgesic potency of the hypnotics they carry. To elucidate possible interactions between lipid emulsions and cell membranes, in particular membrane-bound proteins, we investigated the effects of commercially available lipid emulsions on the cell membrane of cultured cortical neurons and glial cells from the mouse.

Methods: The whole-cell configuration of the patch-clamp technique was used to determine alterations in membrane conductance while the cells were exposed to the emulsions at various dilutions.

Results: Of 9 lipid emulsions tested, 3 (i.e. Intralipid $^{\circledR}$, Structolipid ${ }^{\circledR}$ and, to a much lesser extent, Abbolipid ${ }^{\circledR}$ ) activated membrane currents in the neuronal cells in a dilution-dependent manner. The emulsion-induced currents were not affected by bicuculline and picrotoxin $(100 \mu \mathrm{M})$, but inhibited by ketamine and DL-AP5 $(100 \mu \mathrm{M})$. The voltage dependence of the currents was influenced by the presence of $\mathrm{Mg}^{2+}$ in a way that is typical for currents conducted by NMDA (N-methyl-D-aspartate) receptor channels.

Conclusions: Intralipid ${ }^{\circledR}$, Structolipid $^{\circledR}$ and Abbolipid ${ }^{\circledR}$ activate NMDA receptor channels in cortical neurons. This has to be taken into consideration when lipid emulsions are used as drug carriers.

GRAZ-01-24

Low-grade osteomyelitis after single shot epidural anaesthesia via the caudal approach S. Wittum *, C. Hofer ${ }^{*}$, U. Rölli* , M. Suhner*, J. Gubler ${ }^{\dagger}$, A. Zollinger*

*Institute of Anaesthesiology and ${ }^{\dagger}$ Dept. of Internal Medicine, Triemli City Hospital, Zurich, Switzerland

Introduction: Caudal block, a frequently applied anaesthetic technique in children, has a low incidence of complications [1]. Infections of the epidural space and associated structures occur rarely and have only been described using continuous epidural catheterization [2]. We report a case of a low-grade osteomyelitis after a single shot epidural anaesthesia via the caudal approach.

Case report: A 6-yr-old healthy male had general anaesthesia with sevoflurane and a caudal block for circumcision. The caudal block was performed by single shot technique using a 22-gauge needle under aseptic conditions (disinfection of the skin with octenidinhydro-chloride, use of sterile gloves, face mask and operation, cap). Bupivacaine $20 \mathrm{~mL}$ $0.125 \%$ with epinephrine $1: 200000$ was injected. Anaesthesia and surgical procedure were uneventful. On the third postoperative day, the child presented with immobilizing back pain. He was in a good clinical condition and afebrile. A tender spot in the area of the sacrum without signs of local inflammation was detected. Sensibility and motor function of the legs were preserved. Leukocyte count and C-reactive protein were normal. Magnetic resonance image (MRI) revealed a phlegmonous inflammation at the sacrum. However, the follow-up MRI 17 days later showed an osteomyelitis of the sacrum. The patient was successfully treated with empirical i.v. and later oral antibiotic therapy (amoxicillin and clavulanic acid: $64 \mathrm{mg} \mathrm{kg}^{-1}$ day $^{-1}$ i.v.: 3 days, oral: 46 days); he showed complete recovery.

Conclusions: Back pain after epidural anaesthesia including caudal block is suspicious for an infection in the area of the former puncture and the associated structures, even if signs of local or systemic infection are absent. MRI technique is the appropriate method to detect such infections. However, early MRI may underestimate the full extent of the infection and follow-up examinations for appropriate diagnosis may be required. Empirical antibiotic therapy is justified provided that treatment is successful, hence avoiding surgical intervention.

\section{References}

1. Veyckemanns F, et al. Reg Anaesth 1992; 17: 119-125.

2. Kost-Byerly S, et al. Anesth Analg 1998; 86: 712-716.

GRAZ-01-25

A comparison of propofol- and desflurane-anaesthesia for laparoscopic cholecystectomy

M. Zink, A. Waltensdorfer, G. Weiss, I. Wöhry, M. Rath, J. Engler

Dept. of Anaesthesiology and Intensive Care Medicine, Graz and Leoben, Austria

Introduction: Laparoscopic cholecystectomy, a technique that may even be performed as ambulatory surgery, is known to reduce hospitalization 
time. Consequently the anaesthesia procedure has to be optimized to ensure safe and rapid recovery. We compared two short-acting anaesthetics with regard to post-anaesthesia recovery.

Methods: Total i.v. anaesthesia with propofol was compared with balanced anaesthesia with desflurane for laparoscopic cholecystectomy in 79 patients (ASA I-II) in a prospective trial. In both groups, patients received fentanyl and vecuronium and their lungs were ventilated with an oxygen/air-mixture. Intra- and postoperative haemodynamic variables, oxygen saturation, recovery time from anaesthesia, nausea, pain and analgesic consumption were studied. $P<0.05$ was considered significant.

Results: Patients receiving propofol had lower intraoperative heart rates $\left(69\right.$ beats $\min ^{-1}$ vs. 77 beats $\left.\min ^{-1}, P=0.003\right)$, lower heart rate variability $(P=0.04)$ and fewer attacks of nausea (2 of 44 patients vs. 7 of $35, P=0.03$ ). However, they had a higher consumption of fentanyl (4.3 vs. $\left.3.2 \mu \mathrm{g} \mathrm{kg}^{-1}, P<0.0001\right)$, and a longer time delay until eye opening (11.7 $\mathrm{min}$ vs. $9.5 \mathrm{~min}, P=0.02)$. In contrast pain and analgesic drug consumption was not significantly different between groups during the first $2 \mathrm{~h}$ postoperatively.

Conclusions: Both methods are suitable for laparoscopic cholecystectomy because both enable safe and fast postoperative recovery.

\section{GRAZ-01-26}

Role of nitric oxide in the central nervous system on the development of neurogenic pulmonary oedema in rats

O. Hamdy ${ }^{*}$, K. Nishiwaki*, Y. Shimada*, G.G. Feng ${ }^{*}$, and N. Ishikawa ${ }^{\dagger}$

*Department of Anesthesiology, Nagoya University School of Medicine, Showaku, Nagoya and Department of Pharmacology, Aichi Medical University School of Medicine, Nagakute, Aichi, Japan

Introduction: Sympathetic over-activity may mediate neurogenic pulmonary oedema. It has been reported that vagotomy may also cause neurogenic pulmonary oedema. Thus, vagotomy might be attributed to the lack of afferent nerves or to uncontrolled sympathetic nerve activity. This study evaluates the role of nitric oxide in the central nervous system on the development of neurogenic pulmonary edema.

Methods: Neurogenic pulmonary oedema was induced by injection of fibrinogen and thrombin into the cisterna magna. The physiological role of nitric oxide was evaluated using N-nitro-L-arginine methyl ester or L-arginine. Vagus nerves were either left intact or bilaterally severed. The concentration of neuropeptide Y, a neurotransmitter, in oedema fluid was measured using enzyme-linked immunosorbent assay. Lung water content and protein concentration in oedema fluid were analysed.

Results: With an intact vagus, injection of $\mathrm{N}$-nitro-L-arginine methyl ester worsened pulmonary oedema, whereas L-arginine had no effect. Likewise, the ratio of oedema fluid protein to serum protein was, $6.02 \pm 0.25$, increased by $\mathrm{N}$-nitro-Larginine methyl ester in rats with the vagus nerve intact, and diminished, $4.57 \pm 0.47$, by L-arginine in vagotomized rats. Furthermore, neuropeptide $Y$ concentration in oedema fluid was elevated, -6.77 \pm 0.13 , by $\mathrm{N}$-nitro-L-arginine methyl ester in rats with the vagus nerve intact, and was decreased with $\mathrm{L}$-arginine, $-7.51 \pm 0.16$, in vagotomized rats.

Conclusions: Neurogenic pulmonary oedema is characterized by elevated pulmonary vascular permeability and may be inhibited by nitric oxide production in vagal nerve cells.

\section{GRAZ-01-27}

\section{Midazolam-induced inhibition of intestinal peristalsis in the guinea-pig ileum is not mediated through the benzodiazepine- binding site at the $\mathrm{GABA}_{\mathrm{a}}$-receptor M. K. Herbert ${ }^{*}$, M. Ritter ${ }^{*}$, P. Holzer ${ }^{\dagger}$, N. Roewer* *Dept. of Anaesthesiology, University of Würzburg, Germany and ${ }^{\dagger}$ Dept. of Clin. and Exp. Pharmacology, University of Graz, Austria}

Introduction: Midazolam, routinely used for induction of anaesthesia or for sedation of patients in the ICU, is suggested to contribute to the stasis of gastrointestinal transit in critically ill patients. In order to develop therapeutic strategies to overcome this stasis, it is important to know the mechanisms leading to this inhibition of intestinal propulsion. Thus this study investigates the effect of flumazenil, naloxone, apamin (blocker of low conductance $\mathrm{Ca}^{2+}$-activated $\mathrm{K}^{+}$-channels) on midazolaminduced inhibition of peristalsis in vitro.

Methods: Ileal segments (length $10 \mathrm{~cm}$ ) of guineapigs were mounted in organ baths which contained oxygenated Tyrode's solution $\left(30 \mathrm{~mL}, 37^{\circ} \mathrm{C}\right)$. Prewarmed Tyrode's solution was infused into the intestinal lumen $\left(0.5 \mathrm{~mL} \mathrm{~min}^{-1}\right)$ and after leaving the segment directed into a vertical outlet tubing which ended $4 \mathrm{~cm}$ (reflecting a pressure of $400 \mathrm{~Pa}$ ) above the fluid level of the organ bath. This arrangement caused gradual filling of the intestine. When 
the intraluminal pressure reached a threshold (peristaltic pressure threshold - PPT), an aborally moving wave of peristaltic contraction propelled the intraluminal fluid to leave the system. The PPT $(\mathrm{Pa})$ for eliciting peristaltic waves was used to quantify drug effects. Twenty minutes after pre-treatment with (i) 1 and $10 \mu \mathrm{M}$ flumazenil, (ii) $0.5 \mu \mathrm{M}$ naloxone, (iii) $0.5 \mu \mathrm{M}$ apamin or (iv) Tyrode's solution (vehicle), midazolam $(0.1-100 \mu \mathrm{M})$ was added cumulatively to the organ bath.

Results: Midazolam concentration-dependently enhanced PPT, and peristalsis was always completely inhibited by $100 \mu \mathrm{M}$ midazolam. Pre-treatment with flumazenil did not affect the inhibitory action of midazolam on peristalsis. However, the PPT increase due to midazolam was reduced by naloxone and apamin.

Conclusions: The results confirm the inhibitory action of midazolam on intestinal peristalsis. Unexpectedly the action of midazolam is not mediated through the classical benzodiazepine binding site at the $\mathrm{GABA}_{\mathrm{a}}$-receptor, but involves endogenous opioidergic pathways and activation of $\mathrm{K}^{+}$-channels.

\section{GRAZ-01-28}

\section{Propofol inhibits intestinal peristalsis in the guinea-pig ileum through action on $\mathrm{K}^{+}$channels}

M. K. Herbert ${ }^{*}$, W. Berg ${ }^{*}$, P. Holzer ${ }^{\dagger}$, N. Roewer*

*Dept. of Anaesthesiology, University of Würzburg, Germany and Dept. of Clin. and Exp. Pharmacology, University of Graz, Austria

Introduction: Intestinal transit is often disturbed in ICU patients resulting in increased morbidity and delay in the start of enteral feeding. Sedatives such as propofol are routinely required for treatment of those patients or to enable treatment procedures. Since little is known about the action of propofol on intestinal peristalsis, this study investigates the effect of propofol on intestinal motility in vitro.

Methods: Ileal segments (length $10 \mathrm{~cm}$ ) of guineapigs were mounted in organ baths which contained oxygenated Tyrode's solution $\left(30 \mathrm{~mL}, 37^{\circ} \mathrm{C}\right)$. Prewarmed Tyrode's solution was infused into the intestinal lumen $\left(0.5 \mathrm{~mL} \mathrm{~min}^{-1}\right)$ and after leaving the segment directed into a vertical outlet tubing which ended $4 \mathrm{~cm}$ (reflecting a pressure of $400 \mathrm{~Pa}$ ) above the fluid level of the organ bath. This arrangement caused gradual filling of the intestine. When the intraluminal pressure reached a threshold (peristaltic pressure threshold - PPT), an aborally moving wave of peristaltic contraction propelled the intraluminal fluid to leave the system. The PPT $(\mathrm{Pa})$ for eliciting peristaltic waves was used to quantify drug effects. Twenty minutes after pre-treatment with (i) $0.5 \mu \mathrm{M}$ apamin, (ii) $0.5 \mu \mathrm{M}$ naloxone, (iii) $10 \mu \mathrm{M}$ bicuculline, or (iv) Tyrode's solution (vehicle), propofol $(0.1-100 \mu \mathrm{M})$ was added cumulatively to the organ bath.

Results: Propofol (0.1-100 $\mu \mathrm{M})$ concentrationdependently increased the PPT; however, it never caused complete inhibition of intestinal propulsion in the doses tested. While bicuculline (antagonist of the $\mathrm{GABA}_{\mathrm{a}}$-receptor) failed to prevent the inhibitory effect of propofol, the increase in PPT was significantly reduced after apamin (blocker of low conductance $\mathrm{Ca}^{2+}$-activated $\mathrm{K}^{+}$-channels) and absent after pre-treatment with naloxon.

Conclusions: Propofol inhibits intestinal peristalsis by increasing the PPT, but is less potent and effective compared to barbiturates or alpha ${ }_{2}$-adrenoceptor agonists, since it did not abolish peristaltic activity. The inhibitory effect of propofol does not seem not to be mediated through binding to $\mathrm{GABA}_{\mathrm{a}}$-receptors, but seems to involve enteric opioidergic pathways and $\mathrm{K}^{+}$-channels.

\section{GRAZ-01-29}

VAE caused by defect central venous catheter in the sitting position

F. Kaltenböck, G. Fuchs, G. Schwarz

Clinical Dept. of Anaesthesiology and Intensive Care

Medicine, University of Graz, Austria

The venous air embolism as a complication of the sitting position in neurosurgery is described in detail in numerous reports [1]. The main cause is the facilitation of air entry by subatmospheric pressure in opened veins and the presence of non-collapsible venous channels. We report on two patients operated on in a sitting position with signs of venous air embolism caused by a defective central venous catheter.

Case 1: A 39-yr-old male was operated on in a sitting position, for a tumour located in the cerebellum. A total venous anaesthesia (propofol $10 \mathrm{mg} \mathrm{kg}^{-1} \mathrm{~h}^{-1}$, cisatracurium $0.09 \mathrm{mg} \mathrm{kg}^{-1} \mathrm{~h}^{-1}$, remifentanil $0.3 \mu \mathrm{g} \mathrm{kg}^{-1} \mathrm{~min}^{-1}$ ) and controlled ventilation with a mixture of oxygen and air $\left(\mathrm{F}_{\mathrm{i}} \mathrm{O}_{2}: 0.4\right)$ was performed. For early detection of venous air embolism Doppler ultrasonography [2] and etCO was used. $30 \mathrm{~min}$ after the beginning of the operation the Doppler ultrasonography sound changed characteristically and air was aspirated via the central venous catheter. Since the surgeons could not find any visible entrance hole for the air the central venous catheter was checked. At the connector a 
crack was found as the possible cause of the air embolism. After insertion of a new central venous catheter the operation was continued without further complication.

Case 2: A 49-yr-old male diagnosed with a cervical spinal tumour (C3) was operated on in a sitting position. Anaesthesia, ventilation and monitoring were performed similarly to the patient in Case 1 . $1 \mathrm{hr}$ after the beginning of the operation a venous air embolism was found. After an unsuccessful search for the cause of the air entrance once again a crack at the connector was detected. A new central venous catheter was used and the operation continued without any further problems.

The risks associated with inserting and removing central venous catheters is well known [3]. The appearance of a venous air embolism more than $30 \mathrm{~min}$ after insertion of a central venous catheter is a rare phenomenon.

These case reports show that in the event of venous air embolism without any visible anatomical cause for air entrance a defective central venous catheter has to be considered.

\section{References}

1. Matjasko J, et al. Neurosurgery 1985; 5: 695-702.

2. Michenfelder JD, et al. Anesthesiology 1972; 36: 164-167.

3. Heckmann JG, et al. Crit Care Med 2000; 5: 1621-1625.

GRAZ-01-30

Continuous right ventricular end-diastolic volume index is more relevant than the use of pressure values to guide interventions to influence cardiac output in cardiac surgical patients

W. Zink ${ }^{*}$, H. Rauch*, R. DeSimone ${ }^{\dagger}, J_{*}$ Nöll*, J. Motsch ${ }^{*}$, E. Martin ${ }^{*}$, B. W. Böttiger ${ }^{*}$

${ }^{*}$ Depts of Anaesthesiology and ${ }^{\dagger}$ Cardiac Surgery,

University of Heidelberg, Germany

Introduction: As the impact of right ventricular function on cardiac performance is increasingly recognized, a new pulmonary artery catheter (PAC) has been developed to assess right ventricular parameters and cardiac output continuously. Using this new PAC, we evaluated the association between pressure preload indicators (central venous pressure, CVP; pulmonary artery wedge pressure, PAWP; continuously measured right ventricular end-diastolic volume index, cRVEDVI) and continuous cardiac output (cCO) in cardiac surgical patients.

Methods: Following institutional approval and informed consent, patients undergoing elective coronary artery bypass grafting were studied. A new PAC (CEDV-Catheter $744 \mathrm{H}^{\circledR}$; Baxter Healthcare Corp., Irvine, CA, USA) connected to a computerized monitoring system (Vigilance ${ }^{\circledR} \mathrm{CCO} / \mathrm{SvO}_{2} / \mathrm{CEDV}$; Baxter Healthcare Corp.) was used to determine CVP, PAWP, cRVEDVI, and cCO. Measurements were recorded at eight predefined time points $(1 \mathrm{~h}$, $2 \mathrm{~h}, 3 \mathrm{~h}, 4 \mathrm{~h}, 6 \mathrm{~h}, 8 \mathrm{~h}, 10 \mathrm{~h}$, and $12 \mathrm{~h}$ ) after weaning from cardiopulmonary bypass. Statistical analysis was performed using linear regression of data pairs and Pearson's correlation coefficient (r).

Results: Overall, 80 measurements have been conducted in 10 patients $(60.8 \pm 7.9 \mathrm{yr})$. During the entire study period, no correlation was found between CVP and $\mathrm{CCO}(\mathrm{r}=0.27 ; P=$ n.s. $)$, and between PAWP and $\mathrm{cCO}(\mathrm{r}=0.32 ; P=\mathrm{n} . \mathrm{s}$.). In contrast, a significant positive correlation was documented between cRVEDVI and $\mathrm{cCO}(\mathrm{r}=0.68 ; P<0.01)$.

Conclusions: These data indicate that continuous assessment of right ventricular volume parameters like cRVEDVI is clinically more relevant than the use of pressure values with regard to the haemodynamic state of the patient. In conclusion, the new $\mathrm{PAC}$ is a useful monitoring device to guide interventions to influence $\mathrm{CO}$ in cardiac surgical patients.

\section{Reference}

1. Cheatham ML, et al. Crit Care Med 1998; 26: 1801-1806. 